\title{
CONTEXTOS E IDENTIDADES CULTURALES EN EL SIGLO XXI EN CANADÁ
}

\section{CONTEXTS AND CULTURAL IDENTITIES IN THE 21 ${ }^{\text {st }}$ CENTURY IN CANADA}

\author{
Yoseti Herrera-Guitián ${ }^{1}$
}

\begin{abstract}
RESUMEN
Los procesos culturales que acontecen en la actualidad han dirigido muchas miradas hacia la formación, construcción y transformación de las identidades. La desaparición de las fronteras geográficas y el encuentro entre diversas culturas en un mismo espacio nos obligan a reformular conceptos que comienzan a cambiar nuestra visión sobre la comunicación y las relaciones entre grupos sociales e individuos en general. En el mundo de hoy, en el que la globalización se convierte en catalizadora de diversos movimientos y procesos socio-culturales, históricos e ideológicos, nos enfocamos en el análisis de la identidad cultural en países pluriculturales como Canadá a partir de los contextos situacional y socio-cultural.
\end{abstract}

Palabras clave: identidad cultural; contexto; discurso; multiculturalismo.

\section{ABSTRACT}

Current cultural processes have looked at the formation, construction and transformation of identities. The disappearance of geographical frontiers and the encounter of several cultures in the same space force us to reformulate concepts that have started to change our vision about communication as well as relations among social groups and individuals in general. In a world where globalization turns into a catalyst of diverse movements and socio-cultural, historical and ideological processes, we focus on the analysis of the cultural identity of multicultural countries, such as Canada, taking into consideration its socio-cultural and situational contexts.

keywords: cultural identity; context; discourse; multiculturalism.

Tipología: Artículo de reflexión

Fecha de recepción: 28/05/2015

Fecha de aceptación: 14/08/2015

Como citar este artículo: Herrera-Guitián, Y. (2015). Contextos e identidades culturales en el siglo XXI en Canadá. Jangwa Pana, 14, 113 - 124.

1. Máster en Lengua Inglesa, Universidad de La Habana, Cuba. Correo: setihg@nauta.cu 
La realidad humana solo puede ser social, es necesario, por lo menos, ser dos para ser humano. Hegel

\section{INTRODUCCIÓN}

L a pregunta más universal, la que todos los hombres y mujeres del mundo siempre han querido responder ha sido aquella de quién soy (o quiénes somos). Y es que en esta era, la respuesta a esta inquietud milenaria incluye también el de dónde somos y con quién convivimos, pues la identidad, en tanto proceso de comunicación social, no solo abarca el aspecto psicológico del individuo o de los grupos que la portan, sino también aquel relacionado con el contexto social, histórico y cultural en que se desenvuelven y la manera en que éstos son interpretados por aquellos. "La construcción del sentido de pertenencia está estrechamente relacionada con las interacciones sociales, la cultura y el contexto social micro y macro" (Mercado \& Hernández, 2010, p. 246). De ahí que las identidades sean de carácter dinámico, porque al cambiar los contextos en los que se forman o construyen, cambian también los referentes identitarios (Mercado \& Hernández, 2010) que conforman este fenómeno.

La identidad se refleja en las expresiones de la vida cotidiana de los hombres. Desde las costumbres, tradiciones, hábitos, creencias, valores, normas y el conocimiento compartido en el aspecto más concreto, hasta lo más subjetivo como las expresiones teóricas en el pensamiento social y las creaciones artístico-literarias del grupo social y la comunidad cultural (Fernández \& Fernández, 2012).

En la era posmoderna, uno de los fenómenos que más influye en la formación, transformación y conservación de las identidades es la globalización. Los procesos asociados a ella, que ya no son tan nuevos, se actualizan con formas más so- fisticadas de manipulación e influencia económica y cultural de unos grupos sobre otros.

La política neoliberal establecida por los grupos de poder provoca una avalancha cultural e ideológica sobre las llamadas "minorías", especialmente desde los medios de difusión masiva y el afianzamiento del consumismo capitalista. Esta tendencia implica la instauración de patrones occidentales y eurocéntricos globales en contextos locales. Resultados de esta política de mundialización, como también se le llama (sobre todo en Europa), han sido la fragmentación, el debilitamiento, y la transformación (negativa o positiva $)^{2}$ de las identidades, por un lado, y el fortalecimiento y la creación de grupos de resistencia para su conservación por el otro.

Un elemento de importancia en este fenómeno lo constituyen los movimientos migratorios, pues ello ha provocado la creciente desterritorialización de las identidades y la reformulación de este concepto en función de la variedad de identidades que confluyen en un mismo espacio. Si hace algún tiempo aún se hablaba de identidades a partir de la homogeneidad en términos de lengua, territorio, etnia, entre otros aspectos, hoy lo heterogéneo ya es protagonista, pues se habla de diversidad y mismidad en sociedades que son cada vez más pluriculturales.

La globalización ha tenido un efecto pluralizador sobre las identidades, produciendo una variedad de posibilidades y de nuevas posiciones de identificación. En consecuencia, las identidades se han vuelto más posicionales, más políticas, más plurales y diversas. Y también menos fijas y más unificadas (Shutterberg, 2007).

Con la desaparición o desvirtualización de las fronteras, las referencias culturales de una comunidad pueden ser tan diversas como las memorias históricas de los grupos que la conforman.

2. No se considera el término "pérdida de la identidad" porque en opinión de la autora, las identidades no se pierden, sino que se transforman, aunque en esta transformación ocurra la pérdida de elementos de la identidad precedente. 
Podemos tomar como ejemplo las comunidades en Canadá, en cada una podemos encontrar grupos sociales que difieren en aspectos de tipo étnico, cultural y lingüístico, inmigrantes, nativos, descendientes de inmigrantes (tercera o cuarta generación que ya se consideran "nativos") portan, cada uno, una cultura y memoria histórica dada en su relación con los otros, con el entorno, y en función de su interpretación de estas interacciones. "En ese contexto, el proceso de comunicación que ocurre entre esas entidades culturales (un proceso identitario) se basa en la búsqueda de unidad en esa diversidad" (De la Torre, 2001, p.20).

El análisis que se propone a continuación se desarrolla en torno a los procesos identitarios de los grupos sociales y miembros de sociedades pluriculturales, especialmente en el caso canadiense. Se enfoca en la identidad cultural en contextos como este, pues en ella convergen casi todos los tipos de identidades como son la de género, local, individual, grupal, colectiva, regional y nacional, lo cual nos permite acercarnos más a la producción e interpretación de sentido en estos sujetos y grupos culturales. Coincidimos, además, con Casanovas y Carcásses (2000) en su punto de vista cuando plantean que "todas las identidades son identidades culturales, pues se forman (...) en contextos culturales, discursivos, en contextos de intercambios con otras personas" (p.245).

\section{DISCUSIÓN}

Las identidades tienen carácter multidimensional y multicultural. Las dimensiones de la actividad del ser humano en función de su profesión, género, origen étnico, edad, nivel de escolaridad, posición social, etc., son diversas, así como las identidades que convergen en una misma cultura que, a su vez, contiene otras, de ahí que también se maneje el término identidades fenoménicas ${ }^{3}$.

En cualquier contexto, ambas clasificaciones son válidas, pues los grupos sociales que interactúan:

3. Distintas culturas presentes en una sola cultura nacional. mujeres, maestros, nativos, escritores, polacos, mestizos, contienen identidades y conforman una identidad cultural. El propio dinamismo de este fenómeno nos dice que solo puede definirse o caracterizarse en un momento histórico dado y a partir de productos materiales o espirituales -como pueden ser el discurso, la música, la arquitectura, etc.- de los sujetos culturales que portan dicha identidad.

Partiendo del concepto aportado por De La Torre (2001), quien plantea que la identidad es un proceso que nos permite asumir que "un sujeto, en determinado momento y contexto, es y tiene conciencia de sí mismo, y que esa conciencia de sí se expresa (...) en su capacidad para diferenciarse de los otros, identificarse con determinadas categorías, desarrollar sentimientos de pertenencia, mirarse reflexivamente y establecer narrativamente su continuidad a través de transformaciones y cambios"(p.82) podemos establecer que la otredad tiene un papel esencial en los procesos de mismidad y diferenciación en las identidades.

Según nuestra percepción del otro, ya sea sujeto, grupo, cultura, o sociedad, seremos capaces de identificarnos en una u otra categoría o dimensión social en función de las diferencias. Es en la otredad, en la comparación con el otro, o los otros, que realmente comenzamos a conformar una visión de nuestra identidad. Se establece una distinción entre "nosotros" y "ellos" que generalmente produce expresiones discursivas que van desde la defensa de nuestra cultura como único y "correcto" enfoque de la realidad según las costumbres, valores, ideas, conocimientos, creencias que nos definen, hasta la proyección defensiva hacia esa otra cultura ajena que se contrapone a la nuestra y que sería la otra, la "incorrecta" de acuerdo a los cánones en los cuales hemos vivido.

En las identidades, que se forman y se transforman como procesos de comunicación, ocurre un intercambio entre sujetos de la cultura donde se 
advierten diferencias y semejanzas con el otro. Este proceso, a su vez, produce una serie de acciones espirituales y materiales que denominamos respuestas de identidad.

La identidad se aborda como un sistema encargado de equilibrar dos funciones contradictorias que la caracterizan, por un lado, la defensa de la idiosincrasia ante la agresión del entorno circundante, y por otro, la adaptación a éste. Por ejemplo, un sujeto determinado, portador de una cultura e identidad construidas en un contexto socio-histórico dado, una vez que entre en contacto con otra u otras culturas distintas a la suya, creará respuestas a partir de esta interacción que van a resultar en: asimilación o aculturación (la absorción de una cultura por otra), integración o transculturación (la formación de una nueva cultura) o inserción igualitaria (lo que llamamos pluralismo cultural, en la que el sujeto toma elementos de la cultura establecida e introduce algunos de los suyos, aunque en realidad no siempre ocurre, realmente es más bien teoría utópica, pues solo algunos sujetos culturales tienen la autoconsciencia intercultural para asumir esta respuesta). Estos procesos no dependen solamente de opciones que el individuo tenga la voluntad de elegir conscientemente, sino de otros que influyen en el carácter psicosocial de su identidad, como son las dinámicas de las relaciones de poder entre los grupos y el sentimiento de marginalidad en el caso de los inmigrantes, o pertenencia, en los grupos "ya establecidos" como nativos o locales.

Un ejemplo lo tenemos en las comunidades nativas en Canadá: con el objetivo de "civilizar" a los "salvajes" se crearon las escuelas residenciales para "educar" a los nativos en el idioma, la religión y las costumbres de los anglosajones y los francófonos. El resultado de esta desastrosa medida fue la creación de sujetos desarraigados, con altos índices de adicción al alcohol y a las drogas, propensos a la violencia y al suicidio. De ahí que, además de denominarlos como incivilizados y salvajes, pasaran a considerarlos como una lacra de la sociedad, que debían ser confina- dos a las áreas de las reservas. Fueron despojados de sus identidades, de sus culturas y le fueron impuestas otras que ponían en crisis sus valores, costumbres, tradiciones, que no por ser diferentes son menos valiosas ${ }^{4}$. Los que más derecho tenían a la tierra y a sus riquezas se convirtieron en "minorías", "que no hablan idiomas, sino dialectos, que no profesan religiones, sino supersticiones, que no practican cultura, sino folklore" (Galeano, 1989, p.32), que hoy son renegados y cuyas voces no se escuchan a menos que sea en las lenguas de los grupos dominantes. Los primeros inmigrantes colonizadores y sus descendientes constituyen parte de los grupos de poder que aún no reconocen el aporte de los primeros habitantes a la cultura y la identidad canadienses. En este caso estamos en presencia de un proceso de aculturación frustrada, pues no se despoja totalmente a los individuos de su identidad cultural, y no se logra inculcar en su totalidad la cultura de la mayoría, sino que las identidades de estos grupos resisten a pesar de los esfuerzos por transformarlas o eliminarlas.

En tanto las identidades se formen y se transformen en el mundo de las relaciones sociales, no todos los grupos que participan en ellos tienen las mismas posibilidades para ejercer el poder de identificación, lo que significa que no todos tienen la autoridad para nombrarse a sí mismos. Solo los grupos que tienen esta autoridad están en condiciones de definirse a sí mismos y a los demás. Aunque en 'el país de las sombras largas' hay una preocupación por la cantidad de lenguas nativas actualmente en 'extinción' y por recuperar parte de la memoria histórica que estos grupos han protagonizado, aún se les trata como 'indios' o 'esquimales', por parte de la gran mayoría de los canadienses. Para estas culturas, en su gran mayoría de tradición oral, la lengua constituye una marca identitaria que permea su comportamiento y desarrollo social. La pérdida de este rasgo común en las comunidades más afectadas

4. Consultar: Rebecca Priegert Coulter. Killing Culture: Residential Schools and Canada's First Nations. En VIII Conferencia Internacional sobre Lenguas Extranjeras, Comunicación y Cultura, WEFLA 2012. Holguín. Cuba. Disponible en www.wefla.org 
por este problema afecta sus identidades culturales dentro del mosaico pluricultural en el que conviven.

Castells (2000) plantea que la construcción de sentido y experiencia ocurre en un contexto "marcado" por relaciones de poder. La aspiración de aceptación y de pertenecer a un grupo o sociedad, ante el deseo de continuar siendo uno mismo en relación a su cultura e identidad, es un conflicto que enfrenta todo grupo social e individuo que mantiene una relación de comunicación con otras culturas cuyas estrategias ideológicas pueden ser abrumadoras en cuanto a los discursos que los 'catalogan' como ajenos, extraños, marginados y fuera de los patrones que se consideran válidos. Si bien los inmigrantes que arriban a Canadá se les invita a mantener su nacionalidad: polaco-canadiense, caribeño-canadiense, etc., no es menos cierto que el choque cultural, incluso en relación con otros inmigrantes ya establecidos, es bien difícil, pues se enfrentan a una sociedad con patrones y costumbres totalmente diferentes y grupos diversos dentro del mismo país que evidencian la diversidad de entornos naturales, regionales, culturales, históricos y sociales. La diversidad de respuestas a ello nos devuelve a los resultados que se comentan en el párrafo anterior.

En el Proyecto de Declaración sobre los Derechos Humanos se habla de "la expresión 'identidad cultural' como el conjunto de las referencias culturales por las cuales una persona o un grupo se define, se manifiesta y desea ser reconocido; la identidad cultural implica las libertades inherentes a la dignidad de la persona e integra, en un proceso permanente, la diversidad cultural, el ámbito particular y universal, la memoria y el proyecto" y "se entiende por 'comunidad cultural' un grupo de personas que comparten referencias culturales constitutivas de una identidad cultural común, la preservación y el desarrollo de la cual consideran esencial para su dignidad humana". Los elementos que se señalan en este concepto de identidad cultural, como la libertad inherente y la dignidad, abordan este tema más bien desde una perspectiva política que antropológica y cultural, aunque es válido en función del tratamiento que se le da a las identidades en los contextos multiculturales y en las alternativas políticas que se han formulado para manejar este fenómeno de la forma más 'políticamente correcta'.

Para conceptualizar la identidad cultural, la propuesta de García y Baeza (1996) en su libro Modelo teórico para la identidad cultural (p. 1718) nos parece la más adecuada. Se define este fenómeno como "la producción de respuestas $y$ valores de un grupo social determinado (o de un sujeto determinado de la cultura) que, como heredero y transmisor, actor y autor de su cultura, éste realiza en un contexto histórico dado como consecuencia del principio socio psicológico de diferenciación-identificación en relación con otro(s) grupo(s) o sujeto(s) culturalmente definido(s)".

En primer lugar, se habla de producción de respuestas y valores en el proceso identitario. Este proceso, tanto por su origen como por su función social, es esencialmente comunicativo entre culturas. Por supuesto que los miembros de la sociedad y los grupos que la conforman son los protagonistas de este proceso, pues son portadores, creadores y trasmisores de los objetos espirituales y materiales que los distinguen. El papel que desempeña el contexto en las identidades es esencial, pues no solo estamos refiriéndonos al entorno social, histórico y cultural que influye en los comportamientos de los individuos y grupos sociales, sino cómo éstos visualizan esa realidad circundante y qué elementos consideran relevantes para la producción de su discurso como una de sus formas de representar el mundo y de actuar sobre él al mismo tiempo.

Es por ello que se alude al principio socio psicológico de los sujetos, al proceso de identificación y diferencia en relación al otro o a los otros sujetos y grupos culturales. Ambos procesos ocurren a partir de la percepción de los atributos significativos que cada cual tenga del otro. De 
ahí que se establezcan semejanzas y diferencias que agrupan a unos y otros sujetos en conjuntos determinados. La similitud evidente entre todos los seres humanos los coloca en este gran grupo, pero sus respectivos entornos y las relaciones que se establezcan entre ellos en diversas situaciones y momentos, es lo que históricamente ha ido delimitando las fronteras identitarias. Los actores de las identidades generalmente se encuentran en contextos y situaciones diferentes, por lo que van a tener lecturas diferentes de su propia identidad y de la los otros según sus vivencias, normas, costumbres, proyectos y aspiraciones.

\section{Contextos multiculturales o pluriculturales}

Si bien la identidad cultural implica que las personas o grupos de personas se reconozcan históricamente en su propio entorno físico y social (Molano, citado por Pino-Reyna, 2009, p.38), retomemos nuestro punto de partida, sociedades pluriculturales en las que interactúan portadores de culturas distintas que, aunque se encuentran en un mismo entorno, provienen de contextos distintos que los han provisto de maneras particulares de ver y responder, cuyos referentes difieren de los de otros grupos ${ }^{5}$. De ahí que, en estos casos, el proceso de comunicación entre las culturas produce nuevas respuestas que crean referentes identitarios comunes desde las diferencias. En este sentido, consideremos que grupos heterogéneos desde el punto de vista lingüístico (españoles, cubanos) o étnico (afrodescendientes, chinos) no necesariamente se sentirán identificados con los miembros de su grupo. Lengua y etnia constituyen marcas de identidad, pero no la determinan. Por ejemplo, en el discurso de los sujetos que se desenvuelven en contextos pluriculturales los idiomas oficiales establecidos obligan a las minorías a comunicarse en lenguas que le son ajenas, restándole fuerza a las voces de

5. En este caso nos referimos a sociedades como la estadounidense, en la cual los índices de inmigración se han incrementado exponencialmente en las últimas décadas, y en las cuales convergen grupos sociales y culturales diferentes. También podríamos referirnos a algunos países como el Reino Unido, Australia, algunos países en el área del Mediterráneo y, por supuesto Canadá que es nuestro objeto de estudio. estos grupos en todos los sentidos. Sin embargo, otros referentes como las ideologías compartidas, entre otros, pueden marcar lo común entre ellos.

En contextos multiculturales hay un encuentro de culturas extranjeras en el mismo espacio físico-temporal (aunque en el caso canadiense los espacios son tan diversos como sus culturas ${ }^{6}$ y en un momento histórico dado, pero también de culturas nacionales que se diferencian sustancialmente de otras en la misma sociedad, como es el caso vasco en España, o la cultura quechua en Bolivia. Portadores de una lengua distinta, en muchas ocasiones, a la oficial, estos grupos culturales se ven afectados por relaciones de poder que influyen en la manera de verse a sí mismos y en la manera que la clase dominante los percibe. Sus identidades sufren el impacto de las ideologías que imponen formas de hacer para poder competir con el mercado, formas de comportamiento para sobrevivir, formas de decir para ser escuchados, lo cual provoca conflictos que, por un lado, ponen en crisis sus identidades, y por otro, las reafirman.

$\mathrm{Y}$ es en este entorno que surgen políticas como el multiculturalismo, con Canadá a la vanguardia, que podría interpretarse como una estrategia ideológica de movilización, pues surge como respuesta a la diversidad de culturas en ese país $\mathrm{y}$ al descontento inicial de las minorías, quienes se sentían relegadas políticamente al declararse Canadá nación bicultural y bilingüe debido a la presencia predominante de anglo-descendientes y franco-descendientes. Esta política de inmigración establece un sistema que 'no discrimina' a los ciudadanos por criterios de raza, origen nacional, religión o cultura. Para unos, constituye un ejemplo para alentar a todos los grupos étnicos a mantener y compartir su lenguaje y su herencia cultural con otros grupos con que interactúen,

6. El caso de la identidad canadiense no solo se analiza desde el punto de vista de las diferencias étnicas y culturales dadas por la diferencia de orígenes en sus habitantes (nativos, inmigrantes y locales como resultado de estas etnias), sino desde las diferencias en las regiones políticas y geográficas (32 zonas con diferencias distintivas) de ese país, así como los lenguajes que acompañan a esos grupos con sus respectivos dialectos y variantes de la lengua. 
promoviendo así la tolerancia hacia la diversidad y las actitudes positivas intergrupales; para otros es simplemente una estrategia para generalizar el colonialismo interno. En palabras de Žižek (1988) "el multiculturalismo trata a cada cultura local como el colonizador trata al pueblo colonizado: como 'nativos', cuya mayoría debe ser estudiada y 'respetada' cuidadosamente” (p.171).

A pesar de las políticas creadas por los gobiernos para lograr una tolerancia en la convivencia de una multiplicidad de culturas, la práctica nos dice que falta mucho por hacer en el desarrollo de actitudes positivas hacia las diferencias.

La formación o transformación de la identidad cultural está dada por condiciones objetivas y subjetivas. Objetivas porque el entorno que nos rodea, la realidad circundante y nuestra manera de interpretarla influyen en nuestras representaciones y en las respuestas que tenemos con respecto a ellas. Y subjetivas porque respondemos a partir de nuestras ideologías, actitudes, creencias y normas que compartimos con el grupo o los grupos a los cuales pertenecemos.

Tanto para los nativos y los miembros de los grupos establecidos en Canadá, como para los que recién llegan a formar parte del mosaico, la interacción cultural provoca cambios en sus identidades que pueden ser conscientes, inconscientes o subconscientes, pues aunque algunos se desenvuelven en contextos que les son ajenos (ya sea por el espacio físico o situacional o sus participantes), sus respuestas culturales, de identidad, van a corresponderse con lo que, según los patrones, serán los atributos significativos en ese contexto.

\section{La identidad cultural en Canadá}

El caso de Canadá no es único en el mundo, pues según las estadísticas demográficas solo el 10\% de los países pueden decirse étnicamente homogéneos, pero sí fue una nación pionera en el tratamiento a la diversidad de culturas. Es válido explicar cómo surgió lo que hoy llamamos el patch o mosaico canadiense y cómo se fue conformando la consciencia de una identidad cultural en esta otrora colonia del Reino Unido.

En primer lugar podemos referirnos a la historia de esta nación como colonia y a su proceso de independencia posterior. Este proceso fue lento y progresivo, sin actos de violencia o revoluciones como se ha dado en otros casos históricamente. Gran Bretaña fue entregando poderes políticos, legislativos y administrativos poco a poco, desde 1867, para beneplácito de la mayoría de los canadienses. Estas circunstancias propiciaron la permanencia de muchos atributos y valores ingleses en su cultura. Aún hoy, Canadá forma parte del Commonwealth y los canadienses consideran a la reina como la "jefa de estado". Otro punto significativo es el contenido educativo en el sistema canadiense hasta la primera mitad del siglo XX. Este se centraba principalmente en programas que contenían información referente a la metrópolis, a los grandes clásicos europeos y estadounidenses, y excluía al mismo tiempo aspectos referentes a la historia nacional y a productos de la cultura canadiense, como la literatura, que hasta ese momento eran prácticamente desconocidos.

Otro factor, diríamos esencial, en la identidad cultural canadiense es la política migratoria inclusiva que el gobierno ha mantenido hasta el momento. Los grandes movimientos migratorios, sobre todo durante las Guerras Mundiales, y las características de Canadá como país de gran extensión -que necesita de los inmigrantes para sustentar su economía- fueron motivo para la acogida de personas de todas partes del mundo. Si bien en un inicio no había un principio de selección para estas personas, hoy los requisitos para aceptar inmigrantes son cada vez más exigentes en cuanto a su preparación académica y profesional, lo cual excluye a las personas con menos acceso a la educación en países subdesarrollados y permite a los ya formados y capacitados en distintas ramas emigrar a este país, lo que en otras palabras podría llamarse un proceso 
selectivo de robo de cerebros. No obstante, a los primeros que mencionamos se les contrata para trabajar en los largos períodos de cosecha, pero no se les permite optar por una de las alrededor de 300000 visas anuales que se otorgan?

En la década del 60, como respuesta a la avalancha de inmigrantes de todas las latitudes, se creó una política de inmigración que reconoce plenamente el multiculturalismo. En 1967, durante el mandato del primer ministro Pierre E. Trudeau, surge el Acta de inmigración con un sistema que no discriminaba a los ciudadanos por criterios de raza, origen nacional, religión o cultura. Ya en 1971 la Comisión Real de Bilingualismo y Biculturalismo establece una política para desarrollar la nación sobre la base de una sociedad de descendientes británicos y franceses tomando en cuenta otros grupos étnicos minoritarios. Esta política, creada para alentar a todos los grupos étnicos a mantener y compartir su lenguaje y su herencia cultural con otros canadienses, también perseguía forjar una confianza entre sus miembros, promoviendo así la tolerancia hacia la diversidad y las actitudes positivas intergrupales. Como ya habíamos mencionado, los objetivos que se persiguen con esta política todavía no han sido alcanzados. Algunas comunidades como la nativa se ven afectadas en el tratamiento a su diferencia, pues la transmisión de su lengua y su cultura oral se ve amenazada por el predominio de los idiomas inglés y francés en los sistemas educacionales. Aunque se dan pasos en este sentido, como la creación de escuelas multilingües (español, inglés y francés), para atenuar las diferencias, el gran número de lenguas aborígenes y la falta de personal preparado para enseñarlas hace que muchas de ellas desaparezcan.

Otro elemento en la formación de su identidad

7. Generalmente, se contrata mano de obra barata en países latinoamericanos como México, El Salvador, Nicaragua, etc., que cubren las necesidades de trabajo por seis meses del año. Las condiciones de trabajo y de vida en estos campamentos donde residen por este tiempo es un tema que puede ser y que es tratado por muchos investigadores, sobre todo en el área de los estudios canadienses en Latinoamérica. (Consultar RELEC-Red Latinoamericana de Estudios Canadienses. Ofelia Becerril, Univ. Autónoma Metropolitanana de México; Ariane Souza Santos, Univ. Federal de Minas Gerais en Brasil; Raúl Rodríguez, Univ. De La Habana, Cuba). es la geografía de Canadá, que se erige como protagonista en todos los aspectos de su historia y su cultura. Con treinta y dos zonas naturales definidas, se nos presenta una gama de regiones tan distintas como la tundra, las praderas de Saskatchewan, las montañas de la Columbia Británica, o el suelo rocoso del famoso escudo canadiense.

La naturaleza juega un rol importante en el imaginario nacional de Canadá. La extensión de su territorio, la abundancia de sus recursos naturales y la espectacular belleza de los paisajes son características que han marcado profundamente en desarrollo económico y cultural del país. Todavía hoy una relación privilegiada con la naturaleza es considerada por mucho como un símbolo nacional de los canadienses (Hristoulas, 2005, p.105).

Esta característica ha dado lugar al surgimiento de un instinto de supervivencia muy marcado en los canadienses que no solo se aplica al medio ambiente. "Ellos siempre le están tomando el pulso a la nación como el doctor al enfermo en cama. El objetivo no es comprobar que el paciente mejore sino que viva" (Atwood, 1988, p.165). Su lucha constante es por sobrevivir a la naturaleza, a las grandes potencias colonialistas o imperialistas, a la mayoría en caso de los grupos minoritarios. La escritora Margaret Atwood, en su ensayo Survival plantea que la supervivencia es precisamente el símbolo de los canadienses. "Si tuviera que escoger tres palabras para destilar la esencia de Gran Bretaña, Estados Unidos y Canadá, esas palabras serían isla, frontera y supervivencia" (Atwood, 1988, p.32).

La región adquiere una especial importancia para la identidad de los canadienses. El espacio geográfico que ocupa cada individuo es un sello que los identifica dentro de esta nación de gran diversidad natural. Un entorno común origina caracte- 
rísticas políticas, sociales y culturales comunes. Desde el punto de vista social, las personas que comparten esta realidad y las problemáticas que de ella se generan, van creando lazos de identificación dentro del mismo grupo social y de diferenciación con otras entidades, conformando así su identidad cultural.

La ubicación geográfica de Canadá, justo al lado de Estados Unidos, es otro aspecto importante a considerar en este análisis. La frontera con ese país norteño es el área más poblada debido a condiciones climáticas mas 'benévolas'. El Tratado de Libre Comercio (TLC) entre Canadá, México y los EUA permitió una influencia americana y un dominio preocupante sobre el comercio de Canadá. Si bien es cierto que el país necesita buscar mercado extranjero para las producciones nacionales, no se puede negar que la gran mayoría de las transacciones comerciales se realizan con su vecino del sur.

Esto, a su vez, conlleva una estela de influencia cultural e ideológica considerable sobre sus habitantes. No solo los productos estadounidenses han inundado el mercado canadiense, sino también lo que llamamos hoy los medios de difusión masiva, que han repercutido notablemente para que el ciudadano canadiense, a pesar de su rechazo a los valores del estadounidense, vea su estilo de vida como una meta a alcanzar. Ciertamente no nos extrañe en lo absoluto si confundimos a un canadiense con un americano, como suele suceder, tal es la aparente similitud entre estos dos individuos de diferentes naciones; aunque para los canadienses esta confusión es tomada como un insulto.

De ahí su relación de amor y odio con su vecino del sur. Las relaciones político-económicas entre los dos países tales como el acuerdo sobre las vías marítimas del Ártico y el comercio constante entre ellos, han acercado a sus habitantes considerablemente y a la vez representan una peligrosa influencia sobre los canadienses. Sin embargo, Canadá ha dado muestras en defensa de su sobe- ranía como su negación a participar en la guerra de Iraq y en el proyecto de Homeland Security sobre el escudo antimisiles. Por otro lado, podemos mencionar que el conocimiento que tienen los pobladores sobre sus naciones vecinas es totalmente diferente, Margaret Atwood escribió: "los Estados Unidos siempre se han comportado como los romanos en la Galia: los galos sabían más de los romanos que los romanos de los galos" (Atwood, 1983, p.133). La misma autora (promotora del nacionalismo en Canadá desde los años 60), también se refiere a ello cuando escribió que para los estadounidenses Canadá era ese lugar lejano al cual el tío iba a pescar de vez en vez.

Afortunadamente, Canadá, como país del continente americano, ha comenzado a 'mirar' más hacia el sur en la búsqueda de socios comerciales, políticos y culturales para abrirse a otras posibilidades y apartarse un tanto de su mentalidad euro centrista que los caracterizó hasta bien entrado el siglo XX.

La identidad se moldea en parte por el reconocimiento o la falta de este; a menudo, también, por el falso reconocimiento de otros, y así, un individuo o grupo de personas puede sufrir un verdadero daño o deformación si la gente o la sociedad que lo rodean le muestran, como reflejo un cuadro degradante o despreciable de sí mismo. En el caso de la sociedad canadiense, al compararse con "otros", sus allegados más cercanos son el Reino Unido y los Estados Unidos, dos potencias cuyos antecedentes económicos-sociales y culturales sitúan a Canadá frente a un Goliat más grande de lo que parece. Esta podría ser la explicación para la imagen negativa que tienen los canadienses de sí mismos: no somos estadounidenses, no somos británicos.

\section{Consciencia y formación de la identidad}

Los acontecimientos de la Revolución Tranquila, las luchas del movimiento aborigen en el oeste, $y$ a la instauración del multiculturalismo, como un 
símbolo para los canadienses (amén de sus resultados prácticos) fueron un empuje fundamental en la creación de una consciencia de una identidad canadiense distintiva. Los inicios de los 60 fueron un despertar para esta nación, que abandonó su letargo y se convirtió en un lugar real (Atwood, 1973, p. 85). El conflicto de identidad se hizo más evidente, los símbolos que supuestamente identificaban al canadiense como la artesanía de las Primeras Naciones y los Inuits ${ }^{8}$, no tenían nada que ver con su propia experiencia. Las producciones artísticas locales no despertaban el menor interés a nivel nacional, que prefería los productos extranjeros.

El movimiento nacionalista, promovido por el nacionalismo quebequense, sumado a la promoción de la cultura en general, fue un punto de partida para la búsqueda de esta identidad verdadera que diferenciara a los canadienses del resto del mundo. La fundación de teatros, galerías de arte, librerías y otras instituciones, la inauguración de la mundialmente conocida EXPO 67' contribuyeron de manera significativa a un reconocimiento de las culturas que cohabitan en esa nación del norte. Ya en ese momento se comenzaron a usar símbolos como la bandera (izada por primera vez en 1965) y el himno, que representaban a Canadá como un ente independiente de la metrópolis.

Igualmente, el movimiento nacionalista de los 60 fue decisivo para la implantación de políticas públicas de integración cultural, lo cual sirvió para la reafirmación de identidades étnicas y la fomentación de la cultura en todas sus manifestaciones como forma de reafirmación de una identidad cultural propia.

En cuanto a los habitantes que provienen de Europa, Asia, África y Latinoamérica, los de primera generación ya tienen una identidad que ha sido creada, conformada y alimentada en el entorno en que nacieron y se educaron, vienen dispuestos a mantenerla y en el camino adoptan

8. Primeras Naciones e Inuits: tribus nativas que fueron los primeros habitantes del territorio que hoy conocemos como Canadá. elementos que los ayudan a sobrevivir, pero no cambian en modo alguno su esencia. Ahora, si nos referimos a una segunda, tercera u otras generaciones siguientes, estas adquieren una identidad individual como parte del grupo familiar mezclando elementos de la cultura tradicional de sus antecesores con la cultura social que predomina en su entorno. Recordemos que la formación de las identidades individuales o culturales no es estática sino dinámica, y se mantiene en un proceso de constante cambio y transformación.

Al describir una colectividad, la conciencia y percepción que ese grupo tiene de sí deben estar incluidos siempre. En el caso específico de los canadienses, esta imagen está claramente dañada; durante décadas, los canadienses se han comparado fundamentalmente con dos fuertes potencias: los Estados Unidos y el Reino Unido. Siendo una nación relativamente joven en su desarrollo como país totalmente independiente, su desventaja en muchos aspectos es obvia. Desde el punto de vista económico pueden superarlo, porque cuentan con grandes riquezas naturales, pero con respecto a su cultura, aún prevalece una mentalidad colonial que afecta esta imagen de sí mismos. La metrópolis y el poderoso vecino constituyen ejemplos de lo que quisieran ser en términos de una entidad colectiva identificada para los propios canadienses y para otras naciones a nivel internacional. Este sentimiento de inferioridad que a veces aflora en su discurso puede ser un elemento más a analizar en la formación de una identidad cultural definida.

La llamada crisis de identidad canadiense se origina en la "necesidad de representaciones y significados compartidos que los hagan sentir relativamente similares entre sí y diferentes a otros grupos sociales o naciones" (Tippet, 2000, p.31). La diversidad de culturas, de regiones, de naciones, de lenguas que conviven en este territorio ha sido tema de investigadores y estudiosos que, en su gran mayoría, niegan la existencia de una identidad cultural canadiense y se refieren a la 
presencia de identidades en plural. En este caso, la diversidad constituye un rasgo de identidad, y las actitudes que surgen a partir de eso (relación con los otros "extraños, diferentes" en disímiles entornos y situaciones) y de su relación con la naturaleza que les rodea (también nos referimos a la política y económica), van conformando algunas características que los unen en estas diferencias. No nos referimos a bailes, ni canciones, ni tradiciones culinarias o religiosas, sino a respuestas que, independientemente de estas particularidades, son más o menos comunes y los hacen sentirse parte del mismo grupo.

\section{CONCLUSIÓN}

El fenómeno de la identidad cultural ocurre como respuesta de una comunicación entre culturas. Cualquier interacción que tenemos está sujeta a manifestaciones de nuestra identidad, a contextos y discursos que van a transformarla y a transformar nuestra identidad y la de los otros. Además, constituye uno de los aspectos a través de los cuales podemos conocer mejor los significados producidos por sujetos de otras culturas.

Como proceso de comunicación cultural, la formación, construcción o transformación de la identidad o de las identidades ocurre de manera constante y dinámica, pues la dialéctica misma de las relaciones humanas hace que siempre estemos en intercambio y cambio permanente. Pero ¿qué permea, qué matiza e influye este proceso?: los contextos que acompañan esta comunicación, $\mathrm{y}$, más que el mismo contexto, las representaciones que el ser humano tiene de él, sus respuestas como resultado y cómo ese contacto cultural e identitario transforma ese mismo contexto.

Todo sujeto tiene identidad cultural, todos queremos pertenecer y siempre encontramos otros individuos con los que compartimos características afines, semejanzas lingüísticas, culturales, étnicas, etc. El reto en las sociedades pluriculturales es hallar en esa diversidad de grupos rasgos co- munes no tanto desde el punto de vista tradicional de fusión y mezcla de las características que mencionamos, sino de visión de vida, de ideologías y políticas en función de que cada grupo e individuo se sienta identificado con la diferencia.

La comunicación que se establece entre todas las comunidades culturales en Canadá propicia la formación de un rico mosaico que, política y culturalmente hablando, constituye una fortaleza para la identidad cultural canadiense en general, pero al mismo tiempo origina conflictos en las identidades de los grupos y los sujetos culturales que conforman esta sociedad. Si bien el multiculturalismo surgió como una medida para la convivencia armónica de lo diferente (creado por los grupos en una posición de poder), la concientización de los grupos minoritarios (que en realidad son la mayoría) no ocurrirá hasta que no haya un atisbo de cumplimiento real de lo que se plantea en esta ley. Este elemento constituye un factor esencial para el estudio de la identidad cultural canadiense, y los cambios que se manifiesten en este sentido se tomarán en cuenta según el momento histórico y social que se defina para llevar a cabo este análisis.

\section{REFERENCIAS BIBLIOGRÁFICAS}

Atwood, M. (1973). "Nationalism, Limbo and the Canadian Club". En Atwood, M., Second Words (pp. 83-89). Boston: Beacon Press

Casanovas Pérez, A., \& Carcásses, A. I. (2000). "Acciones dinamizadoras de la participación de los cubanos en la cultura". En Pensamiento y tradiciones populares: estudios de identidad cultural cubana y latinoamericana (pp. 232 268). La Habana: Centro de investigación y Desarrollo de la cultura cubana Juan Marinello. Castells, M. (2000). The Information Age: Economy, Society and Culture, vol. II: The power of identity, Oxford: Blackwell

De la Torre, C. (2001). Las Identidades. Una mirada desde la psicología. La Habana: CIDI Juan Marinello. 
Fernández-Peña, I. \& Fernández-Peña, I. Pino Reyna, Y. (2009). Género, ideología e iden(2012). "Aproximación Teórica a la identidad cultural”. Ciencias Holguín. Vol 18, No 4. Holguín. Recuperado de: http://www.ciencias. holguin.cu/index.php/cienciasholguin/article/ view/728/636

Galeano, E. (1989). El libro de los abrazos. Madrid: Siglo XXI.

García, M. \& Baeza, C. (1996). Modelo teórico para la Identidad Cultural. La Habana: CIDI Juan Marinello.

Hristoulas, A. (2005). Canadá: política y gobierno en el siglo XXI. México: Instituto Tecnológico Autónomo de México.

Mercado-Maldonado, A. \& Hernández-Oliva, A. (2010). "El proceso de construcción de la identidad colectiva". En Convergencia, Revista de Ciencias Sociales. UAEM, (53), 229-251 tidad en poetisas espirituanas. Sancti Spíritus: Luminaria.

Shutterberg, M. (2007). Identidad y globalización. Elementos para repensar el concepto y su utilización en ciencias sociales. Cuadernos de HIdeas, 1, (1).

Tippett, M. (2000). Expressing Identity (Canadian Culture). CPI.Q. Article 47. Mark Beaver, 80 (1), 18-21.

Žižek, S. (1998). "Multiculturalismo o la lógica cultural del capitalismo multinacional". En Jameson F., Žižek S. Estudios culturales. Reflexiones sobre el multiculturalismo. Paidós: Buenos Aires 